\title{
ON SOME STANDARD OBJECTIONS TO MATHEMATICAL CONVENTIONALISM
}

\begin{abstract}
According to Wittgenstein, mathematical propositions are rules of grammar, that is, conventions, or implications of conventions. So his position can be regarded as a form of conventionalism. However, mathematical conventionalism is widely thought to be untenable due to objections presented by Quine, Dummett and Crispin Wright. It has also been argued that only an implausibly radical form of conventionalism could withstand the critical implications of Wittgenstein's rule-following considerations. In this article I discuss those objections to conventionalism and argue that none of them is convincing.
\end{abstract}

According to Wittgenstein, mathematical propositions are rules of grammar, that is, it would appear, conventions ( $P G$ 190, AWL 156-7, BT 196, RFM 199a), or at least determined by conventions (see Schroeder 2014). A mathematical proposition doesn't describe a fact (RFM 356ef), but serves as a linguistic convention: 'only supposed to supply a framework for a description' (RFM 356f), determining the correct use of language (RFM 165h, 196f): what in a certain area of discourse makes sense and what doesn't (RFM 164bc). So Wittgenstein's position (which he held from the early 1930s to the end of his life) can be labelled as a form of conventionalism.

Perhaps the best-known presentation of conventionalism in the philosophy of mathematics is due to the Logical Positivists, in particular A.J. Ayer, who defended the view that all mathematical truths are analytic (1936). That is to say, they can be derived from a set of conventions defining the meanings of our mathematical symbols. For instance, the conventional definition of the series of natural numbers in terms of addition of 1 (each number $>1$ being defined as its predecessor +1 ) logically implies any correct equation of the form $a+b=c$. Thus, an equation such as ' $7+5=12$ ' can easily be proven by a succession of definitional substitutions. (In this, of course, Ayer contradicted Kant's construal of such an equation as synthetic a priori.)

However, mathematical conventionalism has encountered some strong opposition. W.v.O. Quine and Michael Dummett objected that conventionalism is either circular or cannot account for the logical implications of conventions. Crispin Wright tried to show that conventionalism falls 
foul of an infinite regress. It has also been argued that only an implausibly radical form of conventionalism could withstand the critical implications of Wittgenstein's rule-following considerations. I shall discuss those four objections to conventionalism in turn:

(i) Quine's circularity objection;

(ii) Dummett's objection that conventionalism cannot explain logical inferences;

(iii) Crispin Wright's infinite regress objection;

(iv) The objection to 'moderate conventionalism' from scepticism about rule-following.

\section{(i) Quine's circularity objection}

To begin with, I shall consider Quine's critical discussion of conventionalism in his paper 'Truth by Convention' (1936).

Quine proposes to explain the truth of an analytic statement, such as:

(1) A bachelor is an unmarried man.

as follows: Since the word 'bachelor' is defined to mean 'unmarried man', (1) is equivalent to:

(2) An unmarried man is an unmarried man.

And that is a truth of logic (Quine 1936, 323).

However, that is not a very plausible account of analyticity, as it regards language from the artificial, not to say warped, perspective of formal logic. Logicians may see nothing unnatural in a formula of the form 'A $=\mathrm{A}$ ', or $\forall x(f(x) \rightarrow f(x))$, but (2) is not at all an ordinary English sentence. Figures of speech apart (e.g. 'War is war'), we have no use for such a reduplication of predicates; it is vacuous or, in the terminology of the Tractatus, senseless [sinnlos]. Saying that a predicate applies to things to which it applies is comparable to lifting up a chess piece and emphatically putting it down again on the same square. That is not a move in the game, and similarly, one could well imagine that in our natural language we might shrug off sentences such as (2) as ungrammatical. Just as we teach our children that a grammatical sentence must have subject and predicate, we might well make it another learners' grammar rule that subject and predicate must be different (cf.: 'a chess piece must be moved to another square'). Expressions of the form 'A = A' may of course be used in poetry ('A rose is a rose is a rose') or for rhetorical effects, but just like 'Bachelors, oh, bachelors!' they don't count as declarative sentences, so the question of truth or falsity doesn't arise.

To be sure, we don't as a matter of fact dismiss sentences such as (2) as ungrammatical, but the fact remains that we don't use them, because, in a natural sense of the word, they don't say anything: they are empty and 
pointless. It is a psychological matter that when forced to call them either 'true' or 'false', we find it more natural to call them 'true', but as far as the actual workings of our language are concerned, we might just as well call them 'nonsense' (cf. PI \$252). Hence, for Quine to explain the truth or correctness of an ordinary analytic sentence such as (1) as based on the alleged truth of such a linguistic anomaly as (2) is rather perverse.

A much more natural and plausible explanation of the truth of

(1) A bachelor is an unmarried man.

is to say that it is based on, and an expression of, a semantic norm or convention, namely (Def): that the word 'bachelor' is correctly applied to unmarried men (and nothing else).

It is not an effective objection to the more natural view of analyticity (as due to semantic norms, or the meanings of the words involved) to protest that the existence of such linguistic norms is a contingent matter, whereas analytic truths are supposed to be necessary. This objection rests on a confusion of the internal and the external perspective on a rule-governed activity (cf. Hart 1961, 86-7). The rules of chess, for example, are regarded from an internal point of view as fixed and non-negotiable when one is playing chess. That in a certain game the bishop moved from $\mathrm{c} 1$ to $\mathrm{f} 4$ is a contingent matter; a different move with the bishop or another piece might have been made instead. But that the bishop was not moved from $\mathrm{c} 1$ to $\mathrm{c} 2$ is not a contingent matter, for such a move is illegal. Within chess it is a necessary truth that bishops can move only diagonally, for such are the rules of the game. Again, in a certain position a mate in three moves can be forced. Chess problems are based on the necessity that is produced by the rules treated as fixed and unchangeable: In response to White's move, Black must move and he can only move in such and such a way. That is a necessary truth in chess, obviously due to nothing but the rules, which from the internal point of view of chess players are absolutely binding. And yet, of course, there is also an external point of view from which one can describe the origin and development of the game. Here, from a historical or sociological point of view, the same rules are just contingent conventions, which have changed in the past and may change again, should we at some point decide to play a different version of the game of chess instead. Similarly, we can adopt an external perspective on linguistic meanings: considering their origins and changes over time. But that in no way detracts from their normative force when, taking up an internal perspective, we accept and apply them as they are. While a game is being played and the rules accepted, those rules create necessity, i.e. the must and must not of valid norms. ${ }^{1}$

Having missed the most plausible construal of analytic truths, Quine suggests that 'truth by convention' cannot be due to definitions, as they are only conventions of notational abbreviation (Quine 1936, 322), available to

1 For a more detailed discussion of analyticity, see Schroeder 2009. 
transform truths, but not to found them. Rather, we must look for another sort of convention, namely postulates (331), 'assigning truth' to a certain kind of statement (334). He then proceeds to set up logic axiomatically, presenting three postulates or axioms that suffice for developing the propositional calculus (one of them corresponding to the inference rule of modus ponens: licensing the assignment of truth to any ' $q$ ' given the truth of ' $p \rightarrow q$ ' and ' $p$ '), and hinting at four more to cover the predicate calculus as well. Finally, he presents the following problem:

Each of these conventions is general, announcing the truth of every one of an infinity of statements conforming to a certain description; derivation of the truth of any specific statement from the general convention thus requires a logical inference, and this involves us in an infinite regress. [Quine 1936, 342]

In a word, the difficulty is that if logic is to proceed mediately from conventions, logic is needed for inferring logic from the conventions. Alternatively, the difficulty which appears thus as a self-presupposition of doctrine can be framed as turning upon a self-presupposition of primitives. It is supposed that the if-idiom, the not-idiom, and so on, mean nothing to us initially, and that we adopt the conventions (I)(VII) by way of circumscribing their meaning; and the difficulty is that communication of (I)-(VII) themselves depends upon free use of those very idioms which we are attempting to circumscribe, and can succeed only if we are already conversant with the idioms. [Quine 1936, 343]

If instead of an axiomatic system we use truth tables to present the propositional calculus (as Wittgenstein did in the Tractatus), we can explain the if-idiom by the following diagram:

\begin{tabular}{ll}
$p q$ & $p \rightarrow q$ \\
\hline T T & T \\
T F & F \\
F T & T \\
F F & T
\end{tabular}

The diagram is to be taken to mean that if ' $p$ ' is true and ' $q$ ' is true then ' $p \rightarrow q$ ' is true, if ' $p$ ' is true and ' $q$ ' is false then ' $p \rightarrow q$ ' is false, etc. Thus, in explaining the if-idiom, symbolised by the arrow, we already use the ifidiom. That is the infinite regress, or circularity, Quine is concerned about: we cannot explain, and thus set up, logic (logical concepts) without already using logic (logical concepts). One could also put it, more generally, like this: Every use of language involves logic, yet one cannot explain logic without language. In short, one cannot explain logic (or language) without already using logic (or language). 
The point is a familiar one: one cannot learn one's mother tongue with dictionary and grammar book: through definitions and lists of grammatical rules. Children acquire their first language by imitation and practice, instead. And they are certainly not told during the first stages of learning that the sounds and meanings of our words are conventional. They learn that the colour of grass is called 'green' long before realizing that there are different names for it in other languages and that it could have been different in ours. Does that mean that linguistic meaning and grammar are not in fact conventional? Certainly not.

Towards the end of his article Quine comes close to acknowledging as much, considering that 'it may be held that we can adopt conventions through behaviour, without first announcing them in words; and that we can return and formulate our conventions verbally afterwards, if we choose, when a full language is at our disposal' (Quine 1936, 344). And although he concedes that 'this account accords well with what we actually do' (344), in the end it seems to him too vague and insubstantial:

We may wonder what one adds to the bare statement that the truths of logic and mathematics are a priori, or to the still barer behavioristic statement that they are firmly accepted, when he characterizes them as true by convention in such a sense. [Quine 1936, 344-5]

These questions are not so difficult to answer. That logic and mathematics are a priori means that we can verify their statements without recourse to experience. That is an epistemological observation in need of explanation: How can there be statements-apparently assertions about the way things are-whose truth does not depend on the way things are found to be in the world? A plausible explanation of the apriority of logical and mathematical propositions is that their truth is due solely to the conventional meanings of the words or symbols involved (rather than, say, to some alleged faculty of intuition). To the extent to which we are familiar with their meanings, then, we have no need for further experience in order to convince ourselves of the truth of such propositions.

It is certainly true that an account needs to be given of what it means to say that something is conventional when it was never explicitly introduced as such. The criterion for something being a convention is certainly not (as Quine suggests) that it is 'firmly accepted': Numerous empirical truths have been firmly accepted, without thereby becoming mere conventions, while on the other hand, the acceptance of a convention can be more or less firm: even while a convention is still in force people may be half-hearted about it, regularly considering alternatives.

In order to clarify the concept, consider as a clear example of a convention the use of the English word 'blue' (cf. Hart 1961, 54-6; Schroeder 1998, 41-50): 
(i) There is far-reaching agreement among our linguistic community about the correct spelling, pronunciation, and application of this word.

(ii) Spelling, pronunciation and use of the word are, however, in a certain sense, arbitrary, i.e. not forced upon us by the facts of nature. A different sign with a different pronunciation would be just as serviceable, as illustrated by the equivalent words in other languages. What is more, we are not even compelled by nature to have a word with exactly that meaning. As is well known, the boundaries between different colours are conventional too, drawn differently in different languages. In Russian, for example, there is no equivalent for the English 'blue', but one word for 'dark blue' [синий] and another for 'light blue' [голубой].

(iii) The standard spelling, pronunciation and use of the word are consistently kept and conveyed to new members of the community. Deviations are corrected and those corrections are normally accepted. Significantly, such corrections are based only on the fact that a certain linguistic norm is actually in force; it is not required for an appropriate correction of a deviation that the norm in question be intrinsically justified. Thus, to be entitled to correct someone's spelling, pronunciation or use of the word 'blue' you only need to point out that it is not in agreement with common usage; you do not need to argue that it is a good thing for that English word to be spelt, pronounced or applied as it is. That is a crucial feature of the conventionality of a rule (as opposed to its functionality, for instance): the standard of correctness is constituted by social agreement, and therefore criticisms of deviation need to refer only to that social agreement or acceptance, regardless of whether what is thus socially accepted is intrinsically reasonable or better than possible alternatives.

If, according to those three criteria, linguistic meaning is conventional, so is logic. For logic is just an abstraction from linguistic meaning where it concerns the relations between the truth or falsity of sentences. In a broad sense of the term 'logic', it follows logically from the statement that Jones is a bachelor that Jones is unmarried. Taken in that broad sense, all word meanings are relevant to logic. In a narrower sense of the term, logic is concerned with relations between the truth or falsity of statements that depend only on certain structural words, such as 'not', 'and', 'or', 'if', or 'all', together obviously with the terms used to explain the logical features of such connectives, namely: 'true', 'false', 'proposition', 'implies' etc. Either way, insofar as word meaning is conventional, so is logic, which merely reflects certain semantic aspects of our language. Using words with certain meanings ipso facto involves using logic. For any substantive change in inferences we draw and accept is a change in meaning. (For example, if ' $p v q$ ' is taken to imply ' $p$ ', then ' $v$ ' cannot mean the same as our 'or'.)

One may object that since what is conventional could be otherwise, logic cannot be conventional: for after all, one cannot think illogically. - The first 
reply is that, of course, logic could be otherwise. It is a matter of logic that ' $p$ $\& q$ ' implies ' $p$ '; but we could easily introduce a rule forbidding this inference. Obviously, such a rule would change the meaning of ' $p \& q$ '. 'Logical' means: in accordance with meaning. That one cannot think illogically-that one cannot go against meaning (on pain of producing nonsense), doesn't show that meanings cannot change, and with them our logical inferences. Against this one may want to say that, of course, words could have different meanings; but given their current meanings, their implications couldn't be different. That, it would appear, is 'the hardness of the logical must' (PI \$437), much firmer than mere convention! - However, the implications just are an integral part of the meanings. So what the revised objection boils down to is this: Holding on to the words' current meanings, their meanings couldn't be different. And that's not saying anything.

\section{(ii) Dummett's objection that conventionalism cannot explain logical inferences}

Michael Dummett, in his influential review of the first edition of Wittgenstein's Remarks on the Foundations of Mathematics, presents another, though related, criticism ${ }^{2}$ of the logical positivist account of mathematics. 'Modified conventionalism' is Dummett's label for the logical positivist view that only some necessary truths are 'straightforwardly registers of conventions we have laid down; others are more or less remote consequences of conventions' (Dummett 1959, 494). Dummett objects:

This account is entirely superficial and throws away all the advantages of conventionalism, since it leaves unexplained the status of the assertion that certain conventions have certain consequences. [Dummett $1959,494]$

More recently, Dummett's objection has been urged by Michael Wrigley:

The more usual form of conventionalism, associated with Logical Positivism, held that certain basic necessary truths owed their necessity purely to our having an explicit convention to that effect, and that all other necessary truths were consequences of these basic conventions. This theory of necessity is immediately attractive because it removes the epistemological mystery from necessary truth. Its crucial flaw, however, is its inability to explain this notion of consequence. The fact that such-and-such basic conventions have such-and-such consequences is a necessary truth but it cannot be a basic convention. What then is the source of its necessity? [Wrigley 1980, 349-50]

2 Perhaps Dummett's criticism was inspired by Quine's remark, quoted above, that: 'logic is needed for inferring logic from the conventions'. 
However, it is difficult to see the force of this objection. The picture seems to be something like this: We stipulate a set of axioms, say, the nine axioms of Frege's Begriffsschrift:

$$
\begin{array}{l|l}
\text { 1. } & -A \rightarrow(B \rightarrow A) \\
\text { 2. } & -[A \rightarrow(B \rightarrow C)] \rightarrow[(A \rightarrow B) \rightarrow(A \rightarrow C)] \\
\text { 3. } & -[D \rightarrow(B \rightarrow A)] \rightarrow[B \rightarrow(D \rightarrow A)] \\
\text { 4. } & -(B \rightarrow A) \rightarrow(\sim A \rightarrow \sim B) \\
\text { 5. } & -\sim A \rightarrow A \\
\text { 6. } & -A \rightarrow \sim \sim A \\
\text { 7. } & -(c=d) \rightarrow(f(c) \rightarrow f(d)) \\
\text { 8. } & -c=c \\
\text { 9. } & -\forall a f(a) \rightarrow f(c)
\end{array}
$$

How then do we get from those axioms to any other logical truth, not among them, for instance:

$$
\forall x(f(x) \rightarrow g(x)) \rightarrow(g(a) v \sim f(a))
$$

Presumably, (c1) is a consequence of the axioms, but how it follows from them hasn't been explained.

Something like that would appear to be the picture behind Dummett's complaint-but it can be quickly dismissed by simply completing the account of Frege's calculus. For those nine axioms are not the only conventions in Begriffsschrift. There are also three derivation rules (viz. Generalisation, Modus ponens, and a substitution rule), which provide a formal explanation of what in this calculus is to count as a 'consequence' of a given formula, and by means of which it is very easy to derive (c1).

That is the obvious answer to Dummett's criticism: Conventions need not take the form of axiomatic statements, they can also be procedural rules, in particular: inference rules, to make explicit the idea of a logical consequence (cf. Bennett 1961). Hence, in the case of an axiomatic system, the idea that a conventionalist, such as Ayer, would lack the resources 'to explain the notion of consequence' is quite groundless.

What about necessary truth in natural languages? As explained above, logical and analytic truths are due to the meanings of words. For example, it characterises the meaning of the word 'if' that a statement of the form ' $p$, and if $p$ then $q$ ' implies ' $q$ '. If we did not acknowledge this consequence we would ipso facto have given a different meaning to the word 'if'. To the extent to which the meanings of words have been fixed, the logical consequences of statements made up of those words have been fixed too. Any unclarity about the logical implications of a statement is an unclarity about the statement's meaning. So on closer inspection, Dummett's worry is just inconsistent. The idea that we might understand a set of explicit linguistic conventions (and hence the vocabulary from which those conventions are formulated 
and which they partly explain), without yet understanding, or being able to work out, how other things follow from those conventions (and are thus also conventionally determined), doesn't make any sense.

In a word, Dummett's mistake is to think of logic as something on top of meaning. ${ }^{3}$ The philosophical picture here is that you can understand the meanings of all the words and statements-and yet not know what logical relations obtain between those statements. Then of course those logical relations, as something separate from meaning, begin to look rather mysteriously 'unexplained'. It is indeed hard to understand what could be the source of such a free-floating, ethereal mechanism of necessity.

\section{(iii) Crispin Wright's infinite regress objection}

Something like, or broadly in agreement with, our response to Quine and Dummett in the preceding sections was already proposed by Jonathan Bennett (1961), trying to show how conventionalism can also explain the notion of logical consequence. Crispin Wright, however, discusses and rejects this reply as unsatisfactory, claiming that it falls foul of an infinite regress, which can be presented as follows:

(1) On the view under discussion ('modified conventionalism'), all necessary truths are either conventions or their implications.

(2) Suppose a set of conventions $C$ implies a statement $Q$.

(3) Now, what is the status of this second-order statement [i] ' $C$ implies Q'?

(4) Expressing a conceptual truth, (i) must be a necessary truth too.

(5) Hence, according to the view under discussion, it must be either an explicit convention or an implication of conventions.

(6) As it's not an explicit convention, it must be an implication of conventions.

(7) But the only conventions on which the truth of (i) depends are the set $C .^{4}$

(8) Hence, [ii] ' $C$ implies " $C$ implies $Q$ ".

(9) But (ii) must be a necessary truth, too.

(10) And not being a convention itself, (ii) must be the implication of conventions.

(11) And again, the only relevant conventions are the set $C$.

(12) Hence, [iii] ' $C$ implies " $C$ implies ' $C$ implies $Q$ '”'.

And so on, ad infinitum (Wright 1980, 347-50).

3 The same mistake was committed more recently by T. Williamson (2006, 13-14).

4 Let us assume that $C$ also contains conventions governing the use of the word 'imply'. 
Wright then argues that this infinite regress provides a fatal objection to the standard ('modified') conventionalist view:

The model thus appears to require that in order to recognise the status of any consequence of initial logical consequence conventions, we have to recognise the same of infinitely many statements. [Wright 1980, 351]

In other words: Wright claims that, according to 'modified conventionalism', in order to understand that $Q$ is implied by a set of conventions $C$, we'd have to understand first that ' $Q$ is implied by $C$ ' is itself implied by $C$. And in order to understand that, we'd have to understand first that " $Q$ is implied by $C^{\prime \prime}$ is implied by $C^{\prime}$ is implied by $C$, and so on and so forth. Hence, in order to understand any inference from a given set of conventions, we'd have to understand an infinity of inferences-which is impossible.

However, that conclusion does not follow. The infinite regress line (1-12) shows how a derived necessary statement allows the construction of a higherorder necessary statement, for which in turn we can construct a higher-order necessary statement, and so on and so forth. But that does not mean that we have to embark on this endless series of constructions. Indeed, it's not even clear that in order to be aware of a given statement's derived necessity we have to be aware of the possibility of endlessly constructing meta-statements in this way.

Consider the following analogous argument:

Suppose $S$ is an English sentence. In order to understand the linguistic meaning of $S$ we have to recognise that:

(i) $S$ is an English sentence.

But (i) is itself an English sentence. In order to understand the linguistic meaning of (i) we have to recognise that:

(ii) (i) is an English sentence.

And so on indefinitely.

However, in order to understand that $S$-say 'It's raining' - is an English sentence, you don't have to recognise that "It's raining" is an English sentence' is itself an English sentence. There is no need to consider that sentence at all. After all, your understanding of 'It's raining' need not even be formulated in a sentence.

Or again: if a statement $S$ is true, then ' $S$ is true' is itself true. And so is: " $S$ is true" is true', and so forth. You can consider, and convince yourself of, the endless possibility of iterating the truth predicate; but you don't have to. You can simply convince yourself that a given statement-'It's raining'is true (say, by looking out of the window), without considering any such possible iterations. 
Like the 'truth'-predicate, the predicate 'is analytic' can always be applied to result of its applications (provided the initial sentence is quoted and not just referred to by a label or an incidental description). "A bachelor is an unmarried man" is analytic' is itself analytic. Again, we can continue the series, but we don't have to.

Similarly, if we present analytic truths as consequences of a set of all semantic conventions (as in Wright's argument), we can easily convince ourselves that this set entails not only a given analytic truth, but also that statement of entailment itself, and so on and so forth. But so what? It does not follow, as Wright seems to think, that, on the moderate conventionalist view, understanding the initial statement (say, that $S$ is analytic) would require that we run through the whole series of iterations: accomplishing 'infinitely many such feats of recognition' (Wright 1980, 351). Indeed, we need not even consider the possibility of such endless iterations.

To recapitulate: None of the objections to (moderate) conventionalism considered so far are convincing. Quine is concerned that explicit statements of linguistic conventions presuppose the use of linguistic conventions, but he half admits himself that conventions need not originate with explicit formulations. Dummett complains that moderate conventionalism leaves unexplained how certain conventions can have certain consequences, but with respect to formal systems that is patently mistaken since the concept of a logical consequence is explained by conventional rules of inference, and with respect to ordinary language it is inconsistent since the understanding of logical implication is simply an aspect of the understanding of linguistic meaning: you cannot have the latter without the former. Finally, Wright argues that statements of logical inference imply an infinite series of metastatements which, per impossibile, one would have to recognise in order to understand the initial inference, but, as explained, that is a non sequitur: the possibility of endlessly constructing such meta-statements does not establish the necessity to do so.

\section{(iv) The objection to 'moderate conventionalism' from scepticism about rule-following}

However, Dummett and Wright believe that there is yet another, more radical and devastating objection to moderate conventionalism, namely Wittgenstein's rule-following considerations. On their reading (largely in agreement with Saul Kripke's (1982)), Wittgenstein has presented a sceptical problem with the very notion of conventional semantic rules. On this view, Wittgenstein argues that it is never 'determined in advance' whether a certain concept applies in a given case, or what is to be the result of a calculation (Wright 1980, 22). That means (according to this reading of Wittgenstein) that it is never determined in advance what is to count as a consequence of 
a given set of conventions. Therefore, they argue, Wittgenstein could not accept 'moderate conventionalism', but had to go for 'full-blooded' or 'radical conventionalism, the view that:

the logical necessity of any statement is always the direct expression of a linguistic convention. That a given statement is necessary consists always in our having expressly decided to treat that very statement as unassailable; it cannot rest on our having adopted certain other conventions which are found to involve our treating it so. This account is applied alike to deep theorems and to elementary computations. [Dummett 1959, 495]

Thus for every new calculation or inference, 'we are free to choose to accept or reject' it (Dummett 1959, 495), provided we all agree on our choice: For right is simply what the community accepts (Wright 1980, 226).

As a response to Wittgenstein's rule-following problem the community view is a complete failure. For if it cannot be fixed in advance what in a given case is a correct application of the concept ' +2 ', then it is equally impossible to fix in advance what in a given case is to count as 'community agreement' (RFM 392c). Both are on exactly the same footing as instances of Wittgenstein's problem: How can a general concept determine its particular applications?

For another thing, in an account of mathematics, the distinction between conventions and their implications ('moderate conventionalism'), far from being a weakness or an embarrassment, is definitely what we want (cf. RFM 228f; PR 248g). For the alternative, the view that all mathematical propositions are conventions is evidently empirically false: in conflict with the facts of mathematical practice. As noted above, the mark of conventionality is that the standard of correctness is constituted by social agreement, and that therefore criticisms of deviation need to refer only to that social agreement or acceptance. That is true of basic definitions in arithmetic. How can you justify your insistence that the successor natural number after 6 is 7 ? Well, that is simply what has been conventionally agreed: what you've been told by teachers and what you find in all the books. But things are very different with the claim that $7,957 \times 23,249=184,992,293$. The reason I can give for insisting on this equation is not that this just is what everybody accepts-I haven't encountered any acceptance of this sum yet, neither by teachers, nor in books, nor by anybody else; rather, my reason for accepting it is that (I convinced myself that) it is what one gets if one carries out a certain kind of procedure for long multiplications. (And note that, pace Wittgenstein's metaphor (RFM 165), taken up by Dummett $(1959,496)$, there is as a matter of fact no 'putting in the archives' of such new sums either: my accepting that sum now will not be invoked by future mathematicians in order to justify their acceptance of it afterwards. They will never know of my calculations, and even if they did, the fact that I believe this to be the right result will carry no normative force against the standard procedural criteria.) Empirically speaking, there is no 
social agreement on this particular sum, there is social agreement only on the general principles of multiplication. Hence it is not the particular sum that is treated as a convention, but the rules of multiplication. 'Full-blooded conventionalism, refusing to acknowledge the distinction between definitions and calculations, just doesn't agree with our mathematical practice.

Moreover, the idea of 'full-blooded conventionalism' is not only 'hard to swallow' (as Dummett complains), and empirically false, but sheer nonsense. Dummett seems to think, like Quine, that conventionality might simply be a matter of firm acceptance of a given statement, treating it as 'unassailable', so that if we decided to hold a given statement as true come what may we would thereby turn it into a convention. Not so.

To begin with, a particular statement is not a convention, however stubbornly one may hold on to its truth. A convention is an agreement what to do (not just what to believe) under certain repeatable circumstances, in a certain kind of situation, not just on one occasion. Hence a referendum, a one-off decision, is not a convention. Thus we have conventions about how to calculate sums, any sums, i.e. conventions about the use of the addition sign, the multiplication sign, etc. Of course it is conceivable that instead of having the whole system of elementary arithmetic we might only use a few individual formulae, such as ' $5+7=12$ '. In other words, the use of the sign ' + ' might be limited to only a few combinations of numbers. The reason why even in isolation such a single sum could be a convention is that it is general in its application: it is to be used again and again for calculation the overall number of five objects together with seven other objects.

And here already the rule-following considerations come in: For there is a jump from the general formula to its application on a given occasion. (How do I know that ' 7 ' doesn't mean ' 8 ' on a Sunday? How do I know that wooden objects are to be counted in the same way as metal objects?) Indeed even the mere reproduction of the same formula is a case of rule-following: Having agreed to the equation now does not force me to agree to it tomorrow. (Having agreed to 'Today is Sunday' today, I shall reject it tomorrow.) In other words, coming up with a new token of the formula tomorrow because we agreed to one today, is also an inference (cf. PI \$214).

Generality is essential to the very concept of a convention. Any convention requires applications to countless particular cases, i.e. inferences to what to do on a particular occasion. Deciding from case to case, as envisaged by Dummett, simply means not having conventions. Hence Dummett's idea of conventionality without any inferences is a contradiction in terms.

It is important to note how wide the scope of Wittgenstein's rulefollowing considerations is. If, like Dummett, Kripke, and Wright, we took them to show that there could be no rule-governed inferences from the general to the particular, we would have to give up on conventions, most notably on linguistic conventions, and hence on general terms in any kind of statement or utterance. On that reading of the rule-following considerations, 
there could be no concepts with an intension determining their extension. There could simply be no language!

Wittgenstein’s famous rule-following argument (of PI \$\$198-201) is a reductio ad absurdum: If you insist on a certain philosophical account of rulefollowing, rule-following (and hence language) turns out be impossible. So, clearly, that philosophical account of rule-following must be mistaken-it can be seen that there is a misunderstanding here' (PI \$201). ${ }^{5}$ - Obviously, for such an argument to be understood, the absurdity that is presented as a provisional conclusion must be recognized as such. It is crucial that one sees just how devastating the implications of the view in question arewhich is what Dummett and Wright failed to do. Dummett thought that it would undermine just a moderate type of conventionalism, whereas in fact it would do away with conventions, language and all. Wright, like Kripke, thought the damage could be patched up by invoking community agreement, not realising that the recognition of community agreement would itself have become impossible.

The philosophical prejudice that is shown by Wittgenstein to lead to absurdity is the view that for it to be determined that a concept $F$ applies on a particular occasion $o$ it must be unmistakably and compellingly laid down somewhere that $F$ applies on $o$, and so for every possible application. We are particularly inclined to think that for meaning to be fixed in advance of particular applications, there must be something in our heads from which any particular application could be derived with logical necessity. ${ }^{6}$ In the first sections of Part 1 of the Remarks on the Foundations of Mathematics, Wittgenstein makes it very clear that, of course, meaning is determined; only that determination must not be imagined to consist in some sort of infinitely explicit instruction manual in our heads. Meaning is use, and cannot be reduced to, or be based on, mental representation. In short, Wittgenstein's verdict that meaning is not determined by mental representation in the head (see e.g. RFM 409c), is turned by Dummett, Kripke, and Wright into the absurdly radical claim that meaning is not determined full stop (e.g. Wright $1980,22)$, we can never be committed by any semantic convention (232), meanings are always to be freely chosen by us as we go along (Dummett 1959, 495-6). ${ }^{7}$ It would appear that Dummett, Kripke, and Wright belong to the generation of analytical philosophers of whom Bede Rundle remarked that they no longer have a nose for nonsense; and of the latter two one can even say that they appear to have a taste for it (Rundle 1997, ix-x).

5 For a more detailed account of the dialectic of Wittgenstein's rule-following discussion, see Schroeder 2006, 185-201.

6 Wittgenstein also considers ostensive definitions (PI \$\$27-64) and Platonist ideas of a foundation of meaning (PI \$\$191-7), but most people today, like Kripke and Wright, seem to find the mentalistic line far more tempting.

7 Wittgenstein says exactly the opposite: 'When I follow a rule, I do not choose’ (PI §219). 
In conclusion, Quine's, Dummett's, and Wright's objections to conventionalism are unsuccessful, and the rule-following considerations do not provide any convincing objection to 'moderate conventionalism' (i.e., the only consistent form of conventionalism) either. It is an egregious misunderstanding to think that Wittgenstein tried to argue against the possibility of inferences from general statements to particular cases. And if his remarks were, perversely, interpreted in such a destructive way they would gainsay not only 'moderate conventionalism', but the very possibility of general concepts, that is, of language. ${ }^{8}$

\section{References}

Ayer, A.J. (1936): Language, Truth, and Logic, London: Victor Gollancz.

Bennett, Jonathan (1961): 'On Being Forced to a Conclusion', Proceedings of the Aristotelian Society suppl. vol. 35, pp. 15-34.

Dummett, Michael (1959): 'Wittgenstein's Philosophy of Mathematics', in: Benacceraf \& Putnam, pp. 491-509 [also in: G. Pitcher (ed.), Wittgenstein. The Philosophical Investigations, London: Macmillan, 1966; pp. 420-47].

Frege, Gottlob (1879): Begriffsschrift, Halle.

Hart, H.L.A. (1961): The Concept of Law, Oxford: Clarendon Press.

Kripke, Saul (1982): Wittgenstein on Rules and Private Language, Oxford: Blackwell.

Quine, W.v.O. (1936), 'Truth by Convention', in: P. Benacerraf \& H. Putnam (eds), Philosophy of Mathemtaics: Selected Readings, Englewood Cliffs, New Jersey: Prentice-Hall, 1964; pp. 322-345.

Rundle, Bede (1997): Mind in Action, Oxford: Clarendon Press.

Schroeder, Severin (1998): Das Privatsprachen-Argument. Wittgenstein über Empfindung \& Ausdruck, Paderborn: Schöningh; Mentis, 1999.

Schroeder, Severin (2006): Wittgenstein: The Way Out of the Fly-Bottle, Cambridge: Polity.

Schroeder, Severin (2009): 'Analytic Truths and Grammatical Propositions', in: H.J. Glock \& J. Hyman (eds), Wittgenstein and Analytic Philosophy, Oxford: Oxford University Press, 2009; pp. 83-108.

Schroeder, Severin (2014): 'Mathematical Propositions as Rules of Grammar', in: Grazer Philosophische Studien 89, pp. 21-36.

8 I am grateful to Kai Büttner and an anonymous referee for their helpful comments on an earlier version of this paper. 
Williamson, Timothy (2006): 'Conceptual Truth', Aristotelian Society Supplementary Volume 80 (1): pp. 1-41.

Wrigley, Michael (1980): 'Wittgenstein on Inconsistency', in: S. Shanker (ed.), Ludwig Wittgenstein: Critical Assessments. Vol. 3, London: Routledge, 1986; pp. 347-59.

Wright, Crispin (1980): Wittgenstein on the Foundations of Mathematics, Cambridge/Mass.: Harvard UP.

Ludwig Wittgenstein:

AWL Wittgenstein's Lectures, Cambridge, 1932-1935, ed.: A. Ambrose, Oxford: Blackwell, 1979.

BT The Big Typescript: TS 213, ed. \& tr.: C.G. Luckhardt \& M.A.E. Aue, Oxford: Blackwell, 2005.

PG Philosophical Grammar, ed.: R. Rhees, tr.: A.J.P. Kenny, Oxford: Blackwell, 1974.

PI Philosophical Investigations, eds: P.M.S. Hacker \& J. Schulte, tr.: G.E.M. Anscombe; P.M.S. Hacker, J. Schulte, Oxford: WileyBlackwell, 2009.

PR Philosophical Remarks, ed.: R. Rhees, tr.: R. Hargreaves \& R. White, Oxford: Blackwell, 1975.

RFM Remarks on the Foundations of Mathematics, eds: G.H. von Wright, R. Rhees, G.E.M. Anscombe; tr.: G.E.M. Anscombe, rev. ed., Oxford: Blackwell, 1978. 